\title{
Alcohol policy process in Malawi: Making it happen
}

\author{
Carina Ferreira-Borges ${ }^{1}$, Dag Endal ${ }^{2}$, Thomas Babor ${ }^{3}$, Sonia Dias $^{4}$, Maganizo Kachiwiya ${ }^{5}$, and Nelson \\ Zakeyu $^{6}$
}

${ }^{1}$ Instituto de Higiene e Medicina Tropical, Universidade Nova de Lisboa, Portugal. Former Technical Officier at the Regional Office for Africa, World Health Organization

${ }^{2}$ FORUT, Campaign for Development and Solidarity, Norway

${ }^{3}$ University of Connecticut, School of Medicine, Farmington, Connecticut, U.S.A

${ }^{4}$ Instituto de Higiene e Medicina Tropical, Universidade Nova de Lisboa, Portugal

${ }^{5}$ Alcohol Policy Consultant, Malawi

${ }^{6}$ Drug Fight Malawi, Lilongwe, Malawi

\begin{abstract}
Aims: This paper presents the recent history of alcohol-policy development in Malawi, describing changes in the policy process, initiatives to expand the involvement of relevant stakeholders, and efforts to limit the role and influence of vested commercial interests. We also note the challenges that remain for alcohol-policy formulation in Malawi.

Design: We used a holistic, single case-study design to illustrate the process, using information generated from a combination of direct and indirect observations, document reviews, media analysis, and in-depth and semi-structured interviews.

Findings: Alcohol policy development in Malawi reflects a complex combination of political and social processes, fraught with numerous stakeholder conflicts and political power plays. Despite the influence of the alcohol industry in the agenda-setting and consultative process, when adequately resourced and supported, civil society organizations can play an important and productive role in steering policy developments in a sound public-interest direction.

Conclusions: Documenting this type of practical "natural experiment” provides an important opportunity for learning. The Malawi case study reinforces the need for more regular policy analysis of similar initiatives-in particular, in low-income developing countries — and for additional study of the alcohol-policy development process and policy implementation.
\end{abstract}

A policy results from a complex interaction of political and social processes. Recent experience in the African region suggests that alcohol policy formulation is no longer the exclusive domain of governmental authority, but rather involves the participation of others who contribute to-and influence-the end result (Bakke \& Endal, 2010; Parry, 2010; Pitso \& Obot, 2011). Because many of those stakeholders represent vested corporate interests, those who promote health and social concerns are well-advised to increase their understanding of the policy-development process, the actors involved, and the political implications of their actions.

In the case of alcohol policies, health ministries play a crucial role in bringing together the governmental agencies and relevant interest groups needed for effective policy design and implementation. This brings to the table different government sectors such as social welfare, transport, agriculture, policing and law enforcement, trade, industry, commerce, and finance, as well as nongovernmental organizations advancing social, health, economic justice, and faith issues, and economic operators that promote the business interests of alcohol producers, distributors, and retailers, and their allies in the advertising and media industries. In this scenario, alcohol policies have become a "product of competing interests, values and ideologies." (Parry, 2010)

As in many other areas of political activity, promoting the public good requires conscious and coherent organization and planning. Important elements in policy development include alignment of key interest groups, capacity building, increasing public awareness of alcohol problems and potential interventions, repeated consultation and negotiation with government officials, civil society and other stakeholders, and creating new mechanisms for a

Correspondence: Carina Ferreira-Borges, Instituto de Higiene e Medicina Tropical, Universidade Nova de Lisboa. Rua da Junqueira, ${ }^{\circ} 100$-1340-008 Lisboa, Portugal. Telephone: +351912797519. E-mail: na.carina@gmail.com

Financial support: The study was funded by WHO and FORUT. Resources have been made available by the WHO Regional Office for Africa and by FORUT (2010 data collection)

Declaration of interest: None of the authors has a financial or other relationship with the alcohol or tobacco industries.

Acknowledgments/disclaimer: The views presented in this article are solely those of the authors and do not represent the views or policies of the organizations acknowledged.

Keywords: Alcohol policy, alcohol policy process, policy analysis, policy formulation 
broad collaborative process that will facilitate decision making and strengthen policy implementation (Driessen, Glasbergen, \& Verdaas, 2001). The process also requires a thorough understanding of the roles and interests at stake and a willingness to adhere to strong principles that will ensure that potentially effective alcohol policies are protected from distortion by commercial or vested interests. (Casswell, 2009; Daube, 2010; Jahiel \& Babor, 2007; Moodie et al., 2011). As the policy-making process becomes more complex and more contentious, health activists must focus increasing attention on the politics of alcohol to complement their knowledge of the fixed rules of governance and their understanding of evidence-based approaches to reducing problems related to alcohol consumption.

In this article we describe the organization and evolution of an interactive and participatory alcohol policy process within such a complex set of dynamics. Malawi began developing an alcohol policy in 2007. Situated in southeast Africa, Malawi is bordered by Mozambique to the south, Zambia to the west, and Tanzania to the east. Eighty-five percent of the population lives in rural areas, and the country's economy depends largely on agriculture, including significant tobacco production, which accounts for about $55 \%$ of the country's exports. According to a 2009 WHO STEPS survey, $12.6 \%$ of the adult population aged 25-64 drink alcohol. Of those, 30.3\% of the men and $4.1 \%$ of the women are current drinkers (World, Health Organization (WHO), 2009). Drinkers consume, on average, about 15.5 litres of pure alcohol per year; $30.6 \%$ of male and $14 \%$ of female drinkers engage in heavy episodic drinking (WHO, 2011).

\section{Method}

\section{Research Approach}

The most common approach to the study of public-policy creation disaggregates the process into a number of functional components (Lasswell, 1977). In our case we utilized a conceptual model of the policy cycle that helped us to unravel the political process and better understand the context of policy formulation in Malawi (Young \& Quinn, 2002). For the purposes of the study we divided the policy process into two categories: (1) problem definition and agenda setting and (2) policy formulation.

\section{Study objectives}

The study aimed to (1) document the different stages and actors involved in the policy process and (2) gain an improved understanding of how a national alcohol policy could be developed using a participatory process.

\section{Methodology}

Information for the study derived from a qualitative data collection approach. We used a holistic, single case study design to document alcohol policy development in Malawi (Yin, 2009).

\section{Data collection process}

The research project assigned an in-country consultant to collect information related to the policy process. Data collection was guided by a clear protocol and procedures that provided a format for narrative reporting. Those procedures, based on the WHO's Guide for Documenting and Sharing "Best Practices"' in Health Programs (WHO, 2008), governed the systematic collection of numerous sources of evidence describing the policy process. Data collection lasted from August to October 2011 and drew from multiple sources, including 1) a review of (a) official documents, such as reports and minutes of taskforce meetings and regional consultations, (b) notes and support documents from FORUT, and (c) newspaper articles in The Nation, Malawi News, The Daily Times, and Sunday Times; 2) direct observation of Taskforce and regional meetings; 3) key informants' observations on the outcomes of the meetings; and 4) in-depth interviews with representatives of Drug Fight Malawi, the secretariat for the Taskforce. The project also conducted semi-structured interviews with key persons involved in the policy-development process, including officials at the Ministry of Health. Those interviews explored the different stages of the policydevelopment process and tracked participants' experiences. Table 1 provides a chronological overview of the first stages of the policy cycle. Interview results were reviewed with study participants for accuracy. The collection of multiple sources of data helped substantiate the accuracy of the information and improved the consistency of the findings.

\section{Results}

\section{Defining the problem and setting the agenda}

In 2007, as they had done in other countries throughout the African Region (Bakke \& Endal, 2010), representatives of the alcohol industry supported the government of Malawi in its development of a draft National Alcohol Policy. That industry approach was soon challenged by civil society organizations, which viewed it as overly supportive of industry business and policy initiatives and insufficiently attentive to public health and safety concerns. In April 2008, Drug Fight Malawi, a local non-governmental organization (NGO) active in the prevention of alcohol consumption among youth, spearheaded an effort to reconsider the draft policy, convening a stakeholders' meeting to evaluate partners' interest and willingness in reorienting the policy process in a more participatory and public-health-centered direction. This NGO initiative introduced a new dynamic to the policy-setting process, bringing together representatives from numerous government ministries and civil society organizations and incorporating the views of the broader community. The new process also excluded those groups and companies whose interests were at odds with evidence-based alcohol policy.

The gathering recommended a new agenda for establishing a national alcohol policy in Malawi and stressed the need both to appoint a new lead ministry to lead policy development and to create basic institutional mechanisms 
Table 1

Chronology of events during the policy process in Malawi

\begin{tabular}{|c|c|c|}
\hline Policy Stages & Date & Event \\
\hline \multirow[t]{3}{*}{$\begin{array}{l}\text { Problem Definition } \\
\text { and Agenda Setting }\end{array}$} & 2007 & $\begin{array}{l}\text { Presented in a stakeholders' forum, the first draft of the National Alcohol Policy for Malawi produced } \\
\text { by the alcohol industry was subject to criticism by civil society organizations. }\end{array}$ \\
\hline & & $\begin{array}{l}\text { The outcomes of the meeting created a new agenda, which a) protected the development of a new } \\
\text { National Alcohol Policy from interference by vested interests; b) appointed the Ministry of Home } \\
\text { Affairs and National Defense as the interim lead Ministry; and c) established basic institutional } \\
\text { mechanisms to support policy development, including the designation of the NGO, Drug Fight } \\
\text { Malawi, as (Policy) Secretariat to provide full-time operational services for the policy development. }\end{array}$ \\
\hline & & $\begin{array}{l}\text { The process received pledges of support from external partners, such as the Global Alcohol Policy } \\
\text { Alliance (GAPA), FORUT (Campaign for Development and Solidarity), and the WHO country and } \\
\text { Regional Office for Africa to ensure an evidence-based, participatory national alcohol policy for } \\
\text { Malawi. }\end{array}$ \\
\hline \multirow[t]{11}{*}{ Policy Formulation } & 2008 & $\begin{array}{l}\text { Policy development structures, including a full-time secretariat and a National Alcohol Taskforce } \\
\text { Committee, were established. }\end{array}$ \\
\hline & $2008-2010$ & $\begin{array}{l}\text { Capacity-building and research initiatives were launched, including an international training workshop } \\
\text { on evidence-based alcohol policies, Trainer of Trainers program on alcohol policy, constituent } \\
\text { involvement in international scientific events, and the implementation of a baseline survey on } \\
\text { unrecorded consumption. }\end{array}$ \\
\hline & 2008-2013 & $\begin{array}{l}\text { The consultative process during policy development involved the creation of numerous informational } \\
\text { and background documents that guided discussions and fostered transparency. The following list } \\
\text { identifies and summarily describes the most important of those documents. }\end{array}$ \\
\hline & & $\begin{array}{l}\text { "Discussion paper," a document used for first consultations with key stakeholders that assessed } \\
\text { the situation and needs regarding alcohol consumption in the country (2008). }\end{array}$ \\
\hline & & $\begin{array}{l}\text { "Working paper,” resulting from a revision by the alcohol Taskforce Committee after the } \\
\text { consultations. The document reflected possible national strategies for reducing harmful use of } \\
\text { alcohol in Malawi (2008). }\end{array}$ \\
\hline & & $\begin{array}{l}\text { “Strategy paper,” detailing strategic directions, themes and delivery mechanisms of the proposed } \\
\text { national alcohol policy (2009). }\end{array}$ \\
\hline & & “Working Document,” whose purpose was to facilitate district-wide public consultations (2009). \\
\hline & & $\begin{array}{l}\text { "National Alcohol Policy First Draft,” reflecting the outcome of the review and endorsement by } \\
\text { the Inter-Ministerial Committee on Drugs Control of the Working Document (2009). }\end{array}$ \\
\hline & & “National Alcohol Policy Second Draft,” resulting from public district-wide consultations (2011). \\
\hline & & $\begin{array}{l}\text { “National Alcohol Policy Third Draft,” an outcome of the National Stakeholders’ Validation } \\
\text { Meeting (2011). }\end{array}$ \\
\hline & & $\begin{array}{l}\text { "National Alcohol Policy Fourth Draft,” resulting from a revision by the Taskforce Committee } \\
\text { and incorporating new data from a three-month Alcohol Impact Baseline Survey (AIBS) and } \\
\text { from a round-table dialogue on the alcohol policy for Malawi with the alcohol industry (2013). }\end{array}$ \\
\hline
\end{tabular}

to support the national alcohol policy. Recommendations also included broadening civil society representation in the process by involving NGO networks whose constituents are affected by alcohol consumption.

The new agenda received technical support from several international partners, among them the Global Alcohol Policy Alliance (GAPA), FORUT (Campaign for Development and Solidarity), and the WHO Regional Office for Africa. FORUT, as a development NGO specializing in alcohol prevention, connected key persons in Malawi to international networks that offered additional expertise and guaranteed sustainable funding for the policy process.

\section{Policy formulation Setting up policy development structures and establishing a lead agency}

As a first step, Drug Fight Malawi consulted with participating organizations to determine the structure of the committee that would steer the policy-development process and agree on its specific mandate. This structure, called National Alcohol Taskforce Committee, was initially led by the Ministry of Home Affairs and National Defense. Its members included government ministries, such as Education, Trade, Youth, Health, Gender, and Local Government, as well as agencies such as the Police, Revenue Authority, Road Traffic, and National AIDS Commission. Civil society networks such as Human 
Rights Consultative Committee (HRCC), Malawi Health Equity Network (MEHN), Malawi Economic Justice Network (MEJN), Malawi Network AIDS Organizations (MANASO), Gender Network NGOs, and the National Association for People living with HIV \& AIDS in Malawi (NAPHAM) also participated. Membership was based on participants' adherence to a clear public-health vision based on evidence-based, effective strategies relevant to the reduction of alcohol-related harm.

Later in the process, in January 2011, the Taskforce Committee decided to appoint the Ministry of Health as the permanent lead government agency to direct the further development of the alcohol policy. Responsibility for coordinating the process shifted to the NCDs programme, a division of the Directorate of Clinical Services. With those changes, the Taskforce Committee became an interim technical committee for informing policy decisions under the authority of the Ministry of Health. This Ministry thus assumed the responsibility for making policy decisions and communicating with stakeholders, leaving the Secretariat, Drug Fight Malawi, responsible for the policy consultant and for the emerging costs of meetings and further studies.

\section{Building capacity and gathering data to inform policy making}

During 2009 and 2010 the Secretariat organized several capacity-building activities to strengthen the motivation and ability of Taskforce members to participate effectively in the creation of a national alcohol policy. Those activities focused on developing knowledge and skills related to advocacy of an evidence-based alcohol policy. Members of the committee participated in an international training workshop on that subject and in a "Trainer of Trainers" program on alcohol policy conducted by FORUT and Blue Cross Norway.

The committee also conducted a baseline population survey in 2010, in part to examine the role of unrecorded alcohol consumption in the country, about which there was little reliable data. The results, which indicated that unrecorded alcohol was responsible for serious socio-economic challenges and violence, were used to inform the developing policy document (Drug Fight Malawi, 2010).

\section{Consulting and developing policy documents: from policy papers to draft policy}

Different types of consultations occurred during this process. Monthly task force meetings kept members up to date about progress on the policy and allowed for significant discussion of issues related to document development, follow-up tasks, strategic planning, and the collection of endorsements for the policy papers being developed. Another form of consultation involved districtwide meetings, with both community and government representation.

The consultative process began in April 2008 using a questionnaire, administered to key government, civil society and alcohol-industry representatives through e-mail and face-to-face interviews, that aimed to assess Malawi's alcohol situation and related needs. Key findings were later merged into a "Discussion paper," finalized in April 2008. Following a series of consultative meetings, that paper became the "Working paper" for the policy development process.

Based on the first round of consultations, in March 2009 the Taskforce circulated a "Strategy paper" that detailed strategy orientations, themes and delivery mechanisms for the planned alcohol policy. After comment, revision, and approval by the Taskforce Committee, a "Working Document" for use in district-wide public consultations became available in July 2009. In October 2009, the InterMinisterial Committee on Drugs Control reviewed and endorsed the Working Document, recommending that it constitute the first draft of the National Alcohol Policy.

The district-wide consultations that led to the second draft took place from October 2009 to April 2011 and involved activities in eight districts. The consultations were led by the Taskforce Committee and included traditional chiefs, Members of Parliament, district government officers, civil society organizations, youth and women's groups, political and religious leaders, and the media. In June 2011, the Taskforce Committee convened the National Stakeholders' Validation Meeting, calling for reviews of the second draft from a broader audience, including those stakeholders with an economic interest in alcohol production and sales. This meeting resulted in a third draft of the alcohol policy that, pursuant to Government policy guidance, was validated in July 2011 by the Inter-Ministerial Committee on Drugs Control.

In August 2011, the alcohol industry re-entered the policydevelopment process. In a letter submitted with comments to the draft policy, the industry complained that "producers and retailers, key partners in an effective policy," had been excluded from the consultation process (Chibuku Products Limited \& Carlsberg Malawi Limited, 2011a). Industry's strong protest led to plans for two more consultation meetings, to be held in September 2011. One would assemble members of the National Alcohol Policy Taskforce Committee, and the second would bring the Taskforce Committee and representatives of the alcohol industry together.

The Taskforce review meeting produced two important results. It led to the commissioning of a three-month Alcohol Impact Baseline Survey (AIBS) to collect more data to help broaden the scope of the alcohol-policy problem statement. Additionally, the Taskforce established an ad hoc internal committee to consider, whenever possible and without compromising public health and socio-economic objectives, the integration of industry's contributions into the national policy.

The second consultation, designed to receive the industry comments, was cancelled when industry representatives complained about the restrictiveness of the meeting and refused to participate. Industry instead demanded that a full stakeholders' workshop be convened to present its comments on the policy (Chibuku Products Limited \& Carlsberg Malawi Limited, 2011b). 
In March 2013, with the fourth draft ready, the Secretary for Health called for a round table dialogue with the alcohol industry on the alcohol policy for Malawi. Feedback on the changes made to the third draft was provided and the industry was invited to provide further contributions to the document. The meeting included representatives from several different government sectors, but civil society members participated as observers only. As of November 2013, a revised alcohol policy draft is still under consideration at the Ministry of Health, and it is too soon to tell whether the next version will meet the same high public interest standards set by previous drafts.

\section{Discussion}

This case study documents the process of developing a national alcohol policy in Malawi. We observed that political institutions and public bureaucracies played important roles in the policy-making process. Nonetheless, non-state actors - those who had a concern about particular policy issues or who were likely to be affected by policy developments-influenced the agenda and shaped the policy process as well. Civil society organizations and alcohol business interests all played critical roles in shaping the process and the policy.

This case study captures how a national NGO's participation in the policy arena introduced new dynamics to the process and effected a positive shift in the general progression of health policy development. Three elements seem to have contributed substantially to this shift. First, the involvement of international health and development partners, namely FORUT, provided significant resources, encouragement, and expertise, guaranteeing that the National Taskforce Committee could participate effectively in, and complete, the policy-development process. The second key element involved early organizational and operational planning and the introduction of support mechanisms to build participant capacity, facilitate coordination and communication among the actors, and create a management system that assured appropriate consultation and engagement. Lastly, the Malawi government's decision to assign the secretariat role to an NGO that had the time, motivation, and capacity to manage the policy process through to the end assured broad public participation and a focus on evidence-based policy interventions.

Quite in contrast to developments in other African countries, Malawi designated an NGO, Drug Fight Malawi, to serve as secretariat and coordinator of the country's alcohol-policy process, creating a partnership between that agency and the Ministry of Health, which led efforts to draft the new policy. That confident collaboration between government and civil society seemed to work well throughout the process. To our knowledge, such a division of labor in crafting alcohol policy is entirely unique and has never before been documented and described.

Our review of alcohol policy development in Malawi demonstrates that an effective participatory process can be based on an adequately funded, legitimate organizing structure and sustained educational and motivational activities. This experience can serve as a model for other national governments that might engage in such a policy development process. One key element of the process presents a special challenge and deserves attention: achieving the right balance between encouraging broad stakeholder participation and managing the influence those parties exert on the process and policy outcomes. Care should be exercised to assure that a participatory approach facilitates the creation of effective, public-health-oriented policies.

This study tracked the policy development process only until a draft policy was delivered to the government. Since that time, internal government reviews have been conducted under the leadership of the Ministry of Health, complemented by external consultations with economic operators and civil society. Vested interests have accelerated their lobbying and have sought to change the document and slow its progress. That last-minute interference has clearly contributed to the slow pace of developing a national alcohol policy response.

As of November 2013, a final version of the national alcohol policy had been approved by the management of the Ministry of Health and transmitted to the health committee of the Parliament for members' review. Final approval of the policy lies with the President and the Cabinet.

\section{Conclusion}

This review of the Malawi alcohol-policy experience contributes to an understanding of policy development within a participatory process and highlights some of the challenges to bringing about policy change in developing countries. We found clear evidence that alcohol policies can be shaped within a complex network of government and civil society actors and that broad stakeholder participation in the policy process can positively influence the end result. Broad participation in the policy process and the incorporation of people's views in the final policy document also strengthens ownership among a wide group of stakeholders, who later may provide the necessary public support for the effective implementation of the policy.

This study reinforces the need for more policy analysis in this field and for more on-the-ground research regarding both the public policy development process and policy implementation. Given the current, evolving state of alcohol-policy development in many countries, documenting practical experiences-and the roles of different actors in the process-in places where such attempts are made can be an important source of learning. Those experiences would provide a starting point for adaptation, refinement, and innovation in the alcohol policy-making process, helping countries to improve their management, coordination, and response to public concerns. A solid body of knowledge in this area would allow countries to achieve results more efficiently and quickly and could help moderate some of the possible negative influences that now impede the crafting of effective national policies. 


\section{References}

Bakke, O., Endal, D. (2010). Alcohol policies out of context: Drinks industry supplanting government role in alcohol policies in sub-Saharan Africa. Addiction, $105,22-28$.

Casswell, S. (2009). Alcohol industry and alcohol policythe challenge ahead. Addiction, 104 (Suppl. 1), 3-5.

Chibuku Products Limited and Carlsberg Malawi Limited (August 2011a). Submission to the Republic of Malawi Draft National Alcohol Policy. Retrieved from http://www.drugfightmalawi.com/activities.html. Last accessed: 23 November 2011.

Chibuku Products Limited and Carlsberg Malawi Limited (September 2011b). Letter to Drug Fight Malawi and Ministry of Health Malawi on consultation meeting with industry. Retrieved from http://www. drugfightmalawi.com/activities.html. Last accessed: 23 November 2011.

Daube, M. (2010). Commentary on Adams et al.: Learning from history. Addiction, 105, 591-592.

Driessen P., Glasbergen P., \& Verdaas, C. (2001). Interactive policy-making: A model of management for public works. European Journal of Operational Research, 128, 322-337.

Drug Fight Malawi (2010). The report for the Baseline Survey on Unrecorded Alcohol Use in Malawi. Retrieved from http://www.drugfightmalawi.com/ activities.html. Last accessed: 15 November 2011.

Jahiel, R., \& Babor T. (2007). Industrial epidemics, public health advocacy and the alcohol industry: Lessons from other fields. Addiction, 102, 1335-39.

Lasswell, H. (1977). The Politics of Prevention. Psychopathology and Politics. Chicago, U.S.A.: University of Chicago Press.

Moodie, R., Stuckler, D., Monteiro, C., Sheron, N., Neal, B., . . . Casswell, S. (2013). Profits and pandemics: prevention of harmful effects of tobacco, alcohol, and ultra-processed food and drink industries. Lancet, 381, 670-679. doi:10.1016/S0140-6736(12)62089-3

Parry, C. (2010). Alcohol Policy in South Africa: A Review of Policy Development Processes between 1994 and 2009. Addiction, 105, 1340-1345.

Pitso, J., \& Obot, I. (2011). Botswana alcohol policy and the presidential levy controversy. Addiction, 106, 898905.

World Health Organization (WHO). (2008). Guide for documenting and sharing "Best Practices" in health programs. Brazzaville, Congo: Author.

World Health Organization (WHO). (2011). Global status report on alcohol and health. Geneva, Switzerland: Author.

World Health Organization (WHO). (2009). STEPS country reports. Malawi, 2009. Retrieved from http://www.who.int/chp/steps/2009_STEPS_Article_ Malawi.pdf. Last accessed: 13 July 2013.

Yin, R. (2009). Case study research: Design and methods (4th ed.). Thousand Oaks, CA, United States: Sage Publications.
Young, E., \& Quinn, L (2002). Writing effective public policy papers: A guide to policy advisers in Central and Eastern Europe. Budapest, Hungary: Local Government and Public Service Reform Initiative, Open Society Institute Budapest. 